\title{
PENERAPAN METODE HYPNOTEACHING UNTUK MELIHAT MOTIVASI BELAJAR SISWA PADA MATERI TRIGONOMETRI KELAS X
}

\author{
Ratmi Qori $^{1)}$, Budi Santoso ${ }^{2)}$, Cecil Hiltrimartin ${ }^{3)}$ \\ 1) Mahasiswa Pendidikan Matematika FKIP Unsri \\ 2,3) Dosen Pendidikan Matematika FKIP Unsri \\ E-mail: ratmiqori@gmail.com
}

\begin{abstract}
ABSTRAK
Penelitian ini merupakan penelitian deskriptif kuantitatif yang bertujuan untuk mengetahui gambaran pelaksanaan pembelajaran dengan menggunakan metode hypnoteaching dan melihat motivasi belajar siswa khususnya materi trigonometri kelas X SMA Negeri 1 Indralaya. Subjek penelitian ini adalah kelas X IPA 2 SMA Negeri 1 Indralaya yang berjumlah 33 orang. Teknik pengumpulan data yang digunakan berupa observasi dan angket motivasi belajar siswa. Berdasarkan analisis data hasil penelitian diperoleh bahwa gambaran pelaksanaan pembelajaran menggunakan metode hypnoteaching terlaksana dengan sangat baik dengan persentase $85,4 \%$ dan motivasi belajar siswa dengan menggunakan metode hypnoteaching dikategorikan tinggi dengan rata-rata $84,52 \%$.
\end{abstract}

Kata Kunci : Metode Hypnoteaching, Motivasi Belajar, Trigonometri

\section{PENDAHULUAN}

Trigonometri merupakan satu-satunya materi yang diajarkan di tingkat Sekolah Menengah Atas Menurut Rusdi,dkk (2013) mengatakan bahwa materi trigonometri banyak menggunakan konsep matematika yang tidak nyata. Misalnya dalam segitiga adanya perbandingan nilai sinus, cosinus, tangen suatu sudut dan aturan sinus serta aturan kosinus. Pada pokok bahasan trigonometri siswa cenderung hanya menghafal rumus dan kurang termotivasi untuk memahami konsep trigonometri. berbagai penyebab kurang mampunya siswa dalam memahami matematika khususnya trigonometri di antaranya : (1) penyampaian materi oleh guru kurang efektif, (2) kurangnya motivasi belajar siswa, (3) siswa belum mampu menganalisis permasalahan secara mandiri, dan (4) siswa kurang aktif dalam belajar secara individu maupun kelompok.

Motivasi memberikan arah pada kegiatan belajar, sehingga tujuan yang dikehendaki siswa tercapai. Siswa yang memiliki motivasi belajar yang tinggi akan mempengaruhi hasil belajarnya, hal ini juga diungkapakan oleh Suprijono (2009) yaitu beberapa faktor yang mempengaruhi hasil belajar antara lain latar belakang keluarga kondisi (SMA/MA/SMK) kelas X semester 2 pada kurikulum 2013 revisi 2016. 
Faktor motivasi belajar merupakan faktor yang paling besar pengaruhnya. Motivasi belajar merupakan hal yang penting dan perlu diketahui oleh setiap guru. Salah satu metode yang dapat meningkatkan motivasi belajar siswa ialah metode pembelajaran hypnoteaching. Metode hypnoteaching merupakan metode pembelajaran yang dalam menyampaikan materi, guru memakai bahasa-bahasa bawah sadar yang bisa menumbuhkan ketertarikan tersendiri kepada anak didik (Yustisia,2012). Sejalan dengan peneliti yang pernah di lakukan oleh Diantari,dkk (2014) mengatakan bahwa terdapat 32 siswa atau 94,12\% siswa memperoleh hasil belajar di atas KKM dan 2 siswa atau $5,88 \%$ siswa memperoleh hasil belajar di bawah KKM, hal ini menunjukkan bahwa kecenderungan siswa yang mengikuti pembelajaran dengan metode hypnoteaching dapat meningkatkan motivasi dan hasil belajar siswa. Materi pelajaran yang disampaikan oleh guru menjadi hal yang lebih mudah meskipun materi yang diajarkan tergolong sulit.

\section{METODE PENELITIAN}

Penelitian ini merupakan peneliti deskriptif kuantitatif Tujuan peneliti ini untuk melihat penerapan dan motivasi belajar siswa menggunakan metode hypnoteaching pada materi trigonometri. Subyek dalam peneliti ini adalah siswa kelas X IPA 2 SMAN 1 Indralaya. Pada penelitian ini angket yang digunakan oleh peneliti adalah jenis checklist dan menggunakan angket tertutup yang disertai pilihan jawaban yang tersedia yaitu "Sangat Setuju, Setuju, Tidak Setuju, dan Sangat Tidak Setuju”. Angket motivasi pada penelitian ini digunakan untuk mengukur dan mengetahui motivasi belajar matematika siswa kelas X SMA Negeri 1 Indralaya dalam mengikuti pembelajaran menggunakan metode hypnoteaching.

Setelah dilakukan uji validitas angket didapatlah 19 butir pernyataan yang valid dengan uji relibialitas 0,87 . Teknik analisis data yang dilakukan dalam peneliti ini adalah angket motivasi dan lembar observasi. Teknik pengumpulan data dengan cara observasi ini bertujuan untuk mengetahui keterlaksanaan pembelajaraan matematika menggunakan metode Hypnoteaching. Adapun hal-hal yang diamatin pada obsevasi ini adalah 
Tabel 1. Langkah-Langkah dalam Metode Hypnoteaching

\begin{tabular}{|c|c|c|}
\hline No & $\begin{array}{l}\text { Langkah-langkah dalam } \\
\text { Metode Hypnoteaching }\end{array}$ & Aspek yang Diamati \\
\hline \multirow[t]{3}{*}{1.} & Niat dan Motivasi & $\begin{array}{l}\text { Guru memerintahkan kepada siswa untuk } \\
\text { berniat dan berdoa sebelum pembelajaran } \\
\text { dimulai. }\end{array}$ \\
\hline & & $\begin{array}{l}\text { Siswa berniat dan berdoa sebelum } \\
\text { pelajaran dimulai. }\end{array}$ \\
\hline & & $\begin{array}{l}\text { Guru memberi motivasi kepada siswa } \\
\text { bahwa pembelajaran trigonometri sangat } \\
\text { penting untuk dipelajari. Contohnya untuk } \\
\text { menghitung ketinggian tangga yang } \\
\text { disandarkan ke dinding, menghitung } \\
\text { ketinggian pohon dll. }\end{array}$ \\
\hline
\end{tabular}

-Siswa antusias dan bersemangat untuk

belajar matematika khususnya materi

trigonometri.

2. Pacing

-Pendekatan personal guru dengan

siswa, misalnya ada siswa yang pasif atau

bermasalah di dalam kelas guru tersebut

menanyakan langsung kepada siswa

masalah apa yang sedang dihadapi oleh

siswa tersebut.

-Guru menggunakan bahasa-bahsa yang

mudah dipahami oleh siswa dan sedikit

selipkan bahasa gaul yang dipakai oleh

siswa (oke, let's go, kepo dll )

Siswa tidak merasa takut untuk

mengeluarkan pendapat.

Siswa tertarik kepada guru, artinya

tidak bersikap acuh tak acuh terhadap guru.

Guru menggunakan gerakan dan mimik

sesuai dengan tema pembelajaran. 


\begin{tabular}{|c|c|c|}
\hline \multirow[t]{4}{*}{ No } & \multirow{4}{*}{$\begin{array}{l}\text { Langkah-langkah dalam } \\
\text { Metode Hypnoteaching }\end{array}$} & \multirow[t]{2}{*}{ Aspek yang Diamati } \\
\hline & & \\
\hline & & $\begin{array}{l}\text { Guru mengaitkan tema pembelajaran } \\
\text { dengan kehidupan sehari-hari. }\end{array}$ \\
\hline & & $\begin{array}{l}\text { Siswa mengetahui konteks nyata terkait } \\
\text { materi dalam kehidupan sehari-hari. }\end{array}$ \\
\hline \multirow[t]{3}{*}{3.} & Leading & $\begin{array}{l}\text { Guru mengarahkan pada tujuan } \\
\text { pembelajaran }\end{array}$ \\
\hline & & $\begin{array}{l}\text { Guru memimpin diskusi kelompok peserta } \\
\text { didik }\end{array}$ \\
\hline & & $\begin{array}{l}\text { Siswa aktif dalam diskusi kelompok } \\
\text { serta mampu menjelaskan kembali } \\
\text { kepada teman- teman lainnya. }\end{array}$ \\
\hline \multirow[t]{2}{*}{4.} & $\begin{array}{l}\text { Menggunakan kata- } \\
\text { kata positif }\end{array}$ & $\begin{array}{l}\text { Guru menggunakan kata-kata positif pada } \\
\text { saat proses pembelajaran. }\end{array}$ \\
\hline & & $\begin{array}{l}\text { Siswa menggunakan kata-kata positif saat } \\
\text { proses pembelajaran. }\end{array}$ \\
\hline \multirow[t]{2}{*}{5.} & Memberikan Pujian & $\begin{array}{l}\text { Guru memberikan reward atau penguatan } \\
\text { kepada peserta didik melalui kata-kata atau } \\
\text { gerak tubuh. }\end{array}$ \\
\hline & & $\begin{array}{l}\text { Siswa semakin aktif dalam pembelajaran } \\
\text { setelah diberikan reward atau penguatan. }\end{array}$ \\
\hline \multirow[t]{3}{*}{6.} & Modelling & $\begin{array}{l}\text { Guru memberikan contoh yang baik } \\
\text { kepada peserta didik melalui ucapan }\end{array}$ \\
\hline & & $\begin{array}{l}\text { Guru memberikan teladan yang baik } \\
\text { kepada peserta didik melalui perilaku }\end{array}$ \\
\hline & & $\begin{array}{l}\text { Siswa mencontoh ucapan dan perilaku dari } \\
\text { guru yang baik dan menerapkan dalam } \\
\text { kehidupan sehari-hari. }\end{array}$ \\
\hline 7. & $\begin{array}{l}\text { Menguasai Materi } \\
\text { Secara Komprehensif }\end{array}$ & $\begin{array}{l}\text { Guru menyampaikan materi secara } \\
\text { kontekstual }\end{array}$ \\
\hline
\end{tabular}




\begin{tabular}{|c|c|c|}
\hline No & $\begin{array}{l}\text { Langkah-langkah dalam } \\
\text { Metode Hypnoteaching }\end{array}$ & Aspek yang Diamati \\
\hline & & $\begin{array}{l}\text { Guru memberi umpan balik kepada peserta } \\
\text { didik agar peserta didik aktif } \\
\text { dalam proses pembelajaran. }\end{array}$ \\
\hline & & $\begin{array}{l}\text { Siswa memahami materi yang } \\
\text { disampaikan dan siswa dapat menjawab } \\
\text { pertanyaan-pertanyaan yang ditanyakan } \\
\text { terkait materi yang diajarkan. }\end{array}$ \\
\hline
\end{tabular}

Sumber: Nasoetion, Tahun: 2007

Tabel 2. Persentase Keterlaksanaan Metode

\begin{tabular}{cc}
\hline Persentase & Kategori \\
\hline $81-100$ & Sangat baik \\
\hline $61-81$ & Baik \\
\hline $41-60$ & Cukup baik \\
\hline $21-40$ & Kurang baik \\
\hline $0-20$ & Tidak Baik \\
\hline
\end{tabular}

Sumber: Nasoetion, Tahun: 2007

Angket motivasi belajar siswa yaitu adanya indikator motivasi belajar matematika pada siswa yaitu :

a. Ketekunan dalam belajar

b. Ulet dalam menghadapi kesulitan

c. Minat dan ketajaman perhatian dalam belajar

d. Berprestasi dalam belajar

e. Mandiri dalam belajar

Tabel 3. Persentase Angket Motivasi Belajar

\begin{tabular}{cc}
\hline Persentase & Keterangan \\
\hline $85 \% \leq q \leq 100 \%$ & Sangat tinggi \\
\hline $70 \% \leq q<85 \%$ & Tinggi \\
\hline $55 \% \leq q<70 \%$ & Sedang \\
\hline $45 \% \leq q<55 \%$ & Rendah \\
\hline $0 \% \leq q<45 \%$ & Sangat Rendah
\end{tabular}

Sumber: Riduwan, Tahun: 2007 


\section{HASIL DAN PEMBAHASAN}

Tabel 4. Hasil Angket Motivasi Belajar Matematika Siswa pada Materi Trigonometri dengan Menggunakan Metode Hypnoteaching

\begin{tabular}{|c|c|c|c|c|}
\hline Aspek & Sebelum & Kategori & Sesudah & Kategori \\
\hline a. $\quad$ Ketekunan dalam belajar & \multirow{5}{*}{64,59} & \multirow{5}{*}{ Sedang } & \multirow{5}{*}{84,52} & \multirow{5}{*}{ Tinggi } \\
\hline b. Ulet dalam menghadapi kesulitan & & & & \\
\hline $\begin{array}{l}\text { c. Minat dan ketajaman } \\
\text { perhatian dalam belajar }\end{array}$ & & & & \\
\hline d. Berprestasi dalam belajar & & & & \\
\hline e. $\quad$ Mandiri dalam belajar & & & & \\
\hline Aspek & Sebelum & Kategori & Sesudah & Kategori \\
\hline a. $\quad$ Ketekunan dalam belajar & \multirow{5}{*}{64,59} & \multirow{5}{*}{ Sedang } & \multirow{5}{*}{84,52} & \multirow{5}{*}{ Tinggi } \\
\hline b. Ulet dalam menghadapi kesulitan & & & & \\
\hline $\begin{array}{ll}\text { c. } & \begin{array}{c}\text { Minat dan ketajaman } \\
\text { perhatian dalam belajar }\end{array} \\
\end{array}$ & & & & \\
\hline d. Berprestasi dalam belajar & & & & \\
\hline e. Mandiri dalam belajar & & & & \\
\hline
\end{tabular}

Sumber: Data Primer, Tahun: 2017

Tabel 5. Hasil Angket Motivasi Belajar Matematika Siswa pada Materi Trigonometri Sebelum Mengggunakan Metode Hypnoteaching.

\begin{tabular}{llll}
\hline \multicolumn{2}{c}{ Aspek } & Skor & Kriteria \\
\hline a. & Ketekunan dalam belajar & 69,31 & Sedang \\
\hline b. & Ulet dalam menghadapi kesulitan & 53,03 & Rendah \\
\hline c. & Minat dan ketajaman perhatian & 63,06 & Sedang \\
& dalam belajar & & \\
\hline d. & Berprestasi dalam belajar & 71,96 & Tinggi \\
\hline e. & Mandiri dalam belajar & 61,36 & Sedang
\end{tabular}

Sumber: Data Primer, Tahun: 2017 
Tabel 6. Hasil Angket Motivasi Belajar Matematika Siswa pada Materi Trigonometri Sesudah Mengggunakan Metode Hypnoteaching.

\begin{tabular}{llcc}
\hline \multicolumn{1}{c}{ Aspek } & Skor & Kriteria \\
\hline a. & Ketekunan dalam belajar & 83,71 & Tinggi \\
\hline b. & Ulet dalam menghadapi kesulitan & 75,25 & Tinggi \\
\hline c. & Minat dan ketajaman perhatian & 85,60 & Sangat Tinggi \\
& dalam belajar & & \\
\hline d. & Berprestasi dalam belajar & 96,46 & Sangat Tinggi \\
\hline e. & Mandiri dalam belajar & 82,07 & Tinggi \\
\hline
\end{tabular}

Sumber: Data Primer, Tahun: 2017

Hasil angket motivasi belajar siswa yang menunjukkan terjadi peningkatan pada masing-masing aspek yaitu:

a. Untuk aspek yang pertama ketekunan dalam belajar, dengan indikator kehadiran disekolah, mengikuti proses belajar mengajar dikelas, dan belajar di rumah. Pada aspek ini terlihat motivasi belajar siswa meningkat, di buktikan pada saat proses belajar mengajar materi trigonometri dengan menggunakan metode pembelajaran hypnoteaching keseluruhan siswa selalu hadir untuk mengikuti proses belajar mengajar di dalam kelas. Saat mengikuti proses belajar mengajar dikelas sebagaian siswa aktif dan berani dalam mengeluarkan pendapat serta saat diberikan soal latihan siswa aktif dan mampu menjawab soal latihan yang diberikan oleh guru.

Hal ini sejalan dengan pendapat jaya (2010) mengatakan bahwa hypnoteaching adalah mengaktifkan inner motivation dan mempersuasi siswa, mempersuasi siswa untuk nyaman dan betah dalam belajar. lalu Sardiman (2014) juga mengatakan bahwa dengan motivasi, pelajar dapat mengembangkan aktifitas dan inisiatif, dapat mengarahkan dan memelihara ketekunan dalam melakukan kegiatan belajar.

b. Untuk aspek yang kedua ulet dalam menghadapi kesulitan dengan indikator sikap menghadapi kesulitan dan usaha mengatasi kesulitan. Pada aspek ini motivasi belajar siswa terlihat meningkat, di buktikan pada saat proses belajar mengajar dengan menggunakan metode pembelajaran hypnoteaching materi trigonometri sebagian besar siswa mampu menjawab soal-soal dengan benar serta tidak mudah putus asa dalam menjawab soal- 
soal yang diberikan oleh guru. Seperti saat siswa menjawab soal-soal dari LKS dan soal tes dari guru,terlihat sikap dan usaha siswa dalam menjawab soal-soal

Berkaitan dengan pendapat Navis (2013) mengatakan bahwa hypnos adalah suatu kondisi kesadaran (state of consciousness) yang sangat mudah menerima berbagai saran/sugesti). Karena guru menyampaikan materi secara komprehensif maka materi tersebut akan mudah di kuasai oleh siswa sehingga mereka termotivasi dalam belajar dan tidak putus asa dalam menghadapi kesulitan.

c. Untuk aspek yang ketiga minat dan ketajaman perhatian dalam belajar dengan indikator kebiasaan dalam mengikuti pelajaran dan semangat dalam mengikuti proses belajar mengajar. Pada aspek ini motivasi belajar siswa terlihat meningkat, dibuktikan saat proses pembelajaran dengan menggunakan metode pembelajaran hypnoteaching materi trigonometri sebagian besar siswa selalu memperhatikan saat guru menjelaskan materi serta semangat dalam mengikuti proses belajar mengajar di dalam kelas. Noer (2010) mengatakan saat menggunakan metode pembelajaran hypnoteaching tarik minat dan perhatian siswa dengan Bahasa komunikasi persuasif yang lembut, halus dan mengena. Saat itulah siswa merasa tertarik kepada guru serta semangat dalam proses belajar mengajar lalu memberikan segala perhatian siswa tersebut kepada guru.

d. Untuk aspek yang keempat yaitu berprestasi dalam belajar dengan indikator keinginan untuk berprestasi dan kualifikasi hasil. Pada aspek ini motivasi belajar siswa terlihat meningkat, di buktikan saat proses belajar mengajar didalam kelas dengan menggunakan metode pembelajaran hypnoteaching pada materi trigonometri siswa bersaing antar sesama agar mendapat peringkat didalam kelas, dibuktikan saat diberikan soal latihan siswa mampu mendapatkan nilai yang sangat baik serta saat guru memberikan soal tes nilai keseluruhan siswa mampu menjawab soal-soal dengan baik dan benar. 


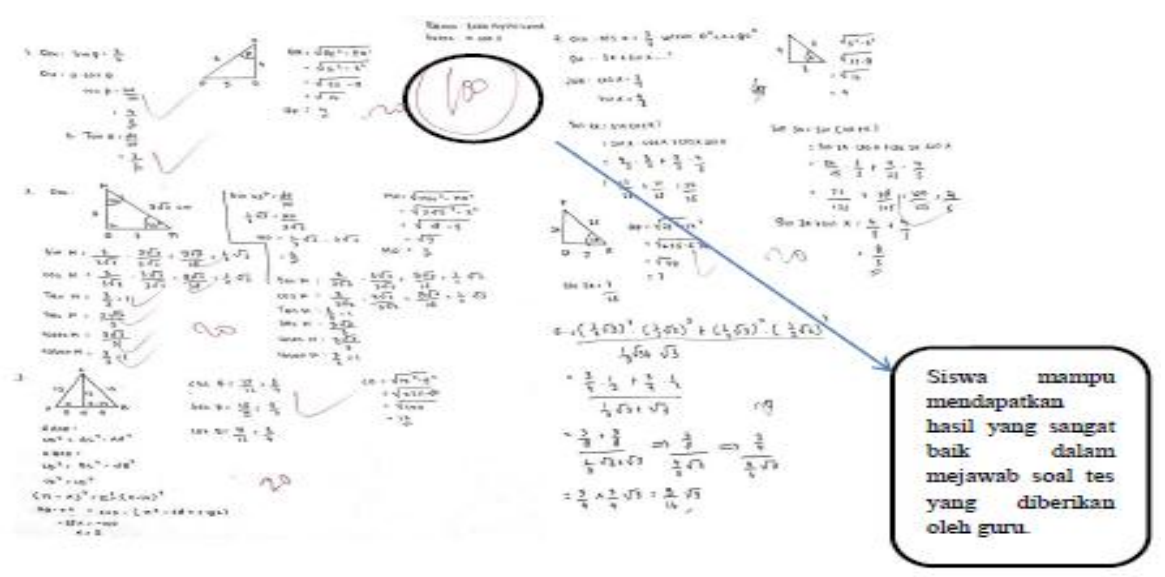

\section{Gambar 1. Siswa mampu menjawab soal tes dengan nilai yang sangat baik.}

Dari gambar diatas siswa mampu menjawab soal tes yang diberikan oleh guru dengan benar dengan nilai yang sangat baik. Berkaitan dengan pendapat Yustisia (2012) mengatakan bahwa salah satu kelebihan dari metode hypnoteaching adalah suasana menjadi rileks dan menyenangkan, hal ini membuat peserta didik merasa senang dan bersemangat ketika mengikuti pembelajaran, serta salah satu manfaat lainnya ialah lebih bisa berimajinasi dan berpikir secara kreatif, hal ini lah yang mendorong siswa dapat berprestasi dalam belajar. Ditambahkan oleh pendapat Sardiman (2014) bahwa adanya motivasi yang baik dalam belajar akan menunjukkan hasil yang baik.

e. Untuk aspek yang kelima yaitu mandiri dalam belajar dengan indikator penyelesaian tugas atau PR dan menggunakan kesempatan diluar jam pelajaran. Pada aspek ini motivasi belajar terlihat meningkat, di buktikan saat proses belajar mengajar di dalam kelas dengan menggunakan metode pembelajaran hypnoteaching sebagian siswa serius dalam mengerjakan tugas yang diberikan oleh guru, menyelesaikan tugas dengan penuh tanggung jawab sehingga mendapatkan hasil yang memuaskan.

Sejalan dengan pendapat Yustisia (2012) yaitu langkah ketiga dari metode hypnoteaching yaitu leading yang berarti memimpin atau mengarahkan. Setelah guru melakukan langkah kedua yaitu pacing, peserta didik akan merasa nyaman dengan suasana pembelajaran yang berlangsung. Ketika itulah hampir setiap apapun yang diucapkan guru atau ditugaskan kepada siswa, siswa akan melakukannya dengan senang hati. 


\section{KESIMPULAN DAN SARAN}

Adapun kesimpulan pada penelitian ini adalah sebagai berikut :

1. Penerapan metode hypnoteaching dikelas X SMA N 1 Indralaya pada materi trigonometri terlaksana dengan sangat baik, adapun langkah-langkah dari metode hypnoteaching yaitu 1. Niat dan Motivasi, 2.Pacing, 3.Leading, 4. Menggunakan katakata positif, 5.Memberikan Pujian, 6.Modeling, 7.Menguasai Materi Secara Komprehensif, dengan rata-rata persentase keterlaksanaan sebesar $85,4 \%$.

2. Motivasi belajar siswa setelah diterapkan pembelajaran dengan menggunakan metode hypnoteaching di SMA N 1 Indralaya secara keseluruhan dikategorikan tinggi dengan rata-rata $84,52 \%$. Adapun ketercapaian dari setiap aspek motivasi belajar yaitu ketekunan dalam belajar dengan persentase $83,71 \%$; aspek ulet dalam menghadapi kesulitan dengan persentase $75,25 \%$; aspek minat dan ketajaman perhatian dalam belajar dengan persentase 85,60\%; aspek berprestasi dalam belajar dengan persentase 96,46\%; aspek mandiri dalam belajar dengan persentase $82,07 \%$.

Adapun saran pada penelitian ini adalah sebagai berikut :

1. Kepada guru, diharapkan dapat menggunakan metode pembelajaran hypnoteaching untuk meningkatkan motivasi belajar siswa.

2. Dalam menjalankan langkah-langkah dari metode hypnoteaching guru harus menyampaikan materi secara kontekstual serta guru mengaitkan tema pembelajaran dengan kehidupan sehari- hari agar siswa lebih aktif dalam pembelajaran 


\section{DAFTAR PUSTAKA}

Diantari, P., Wiarta, I, W,. \& Negara, I, G, A, O,. (2014). Pengaruh Model Pembelajaran Problem Based Learning Berbasis Hypnoteaching Terhadap Hasil Belajar Matematika Siswa Kelas V SD. Jurnal Mimbar PGSD Universitas Pendidikan Ganesha, 2(1).

Jaya, N, T,.(2010). Hypnoteaching Bukan Skedar Mengajar. Jawa Barat Indonesia. D - Brain .

Navis, A, A,.(2013). Hypnoteaching. Jogjakarta. Ar-Ruzz Media.

Noer, M,. (2010). Hypnoteaching For Succes Learning. Yogyakarta. Pedagogi

Sardiman, A, M,. (2014). Interaksi dan Motivasi Belajar Mengajar. Jakarta: Rajawali Pers.

Rusdi. Maulana, D., \& Susanto, E. (2013). Pembelajaran Inkuiri Pada Materi Trigonometri Untuk Meningkatkan Hasil Belajar dan Aktivitas Siswa Kelas X2 SMAN 1 Kota Bengkulu: 456.

Yustisia, N,. (2012). Hypnoteaching Seni Ajar Mengeksplorasi Otak Peserta Didik. Jogjakarta: Ar-ruzz Media 
